\title{
Relationship between food polyamines and gross domestic product in association with longevity in Asian countries
}

\author{
Phan Nguyen Thanh Binh ${ }^{1,2}, K_{\text {Kuniyasu Soda }}^{3^{*}}$, Chizuko Maruyama $^{2}$, Masanobu Kawakami $^{4}$ \\ ${ }^{1}$ Department of Community Nutrition, HCMC Nutrition Center, Ho Chi Minh City, Vietnam; \\ ${ }^{2}$ Department of Food and Nutrition, Japan Women's University, Tokyo, Japan; \\ ${ }^{3}$ Department of Cardiovascular Research Institute, Saitama Medical Center, Jichi Medical University, Saitama, Japan; \\ *Corresponding Author: soda@jichi.ac.jp; \\ ${ }^{4}$ Department of Internal Medicine, Saitama Medical Center, Jichi Medical University, Saitama, Japan.
}

Received 15 October 2010; revised 1 November 2010; accepted 5 November 2010

\section{ABSTRACT}

The relationship between gross domestic product (GDP) and dietary profile, with a focus on polyamine intake, was investigated in 35 Asian countries. Data on food supply, GDP, and health condition were collected from databases of the United Nations, the International Monetary Fund, and the World Health Organization, respectively. The amount of polyamine intake from food was estimated using polyamine concentrations listed in published sources. The amounts of putrescine, spermidine, spermine, and total polyamines in $1000 \mathrm{kcal}$ of food in Asian countries were 39.07 $\pm 17.98,33.74 \pm 14.35,14.05 \pm 6.60$ and $86.85 \pm$ $33.96 \mu \mathrm{mol} / 1000 \mathrm{kcal}$, respectively. Putrescine, spermidine, and spermine constituted 44, 39, and $17 \%$ of total polyamine, respectively. Vegetables contributed the largest amount of both putrescine and spermidine and the second largest amount of spermine $(45.5 \%, 62.2 \%$ and $27.2 \%$ of total putrescine, spermidine, and spermine, respectively). Meat was the richest source of spermine and contributed the greatest amount $(50 \%)$ of this polyamine. We showed a significant positive association between GDP and the amount of polyamine per $1000 \mathrm{kcal}$ of food. Lifespan was associated with both GDP and the amount of polyamine per energy quotient of food. As several basic research studies have shown that polyamines help prolong longevity, it follows that polyamines may have a role in determining the lifespan of humans.

Keywords: Polyamine; GDP; Longevity; Cardiovascular Diseases; Food

\section{INTRODUCTION}

The polyamines putrescine, spermidine, and spermine, not only play an essential role in the proliferation and differentiation of mammalian cells but also have important physiological roles on cellular function. In addition, very recent studies have shown that exogenous polyamine suppresses the progression of age-associated pathologies and increases the life span of cells and several living organisms including mice $[1,2]$. On the other hand, there is evidence that increased polyamine concentrations are associated with several deteriorations in health [3-6].

Food is one of the important sources of body polyamines which are absorbed by the intestinal lumen and then distributed to all organs and tissues [7]. In fact, differences in polyamine intake have been shown to influence blood polyamine concentration in both mice and humans [8]. As most foods originate from plants or animals, almost all foods contain polyamines, but in widely varying concentrations [9-12]. It is therefore very important to delineate the factors that may influence polyamine intake.

Socioeconomic status is closely associated with favorable health status and prolonged lifespan [13-18]. Gross domestic product (GDP) is one of the representative indicators of socioeconomic status of countries, and we have shown using an open database that individuals living in European and Western countries with a high GDP prefer foods containing abundant polyamines compared to individuals living in countries with a lower GDP [19]. This study aimed to examine the relationship between the amount of food polyamine and GDP in Asian countries. In addition, as polyamines have been shown to have several roles on health status in experimental models, we also examined the relationship between health status and polyamine intake in association 
with GDP.

\section{METHODS AND MATERIALS}

\subsection{Database}

Data on food supply in 2002 were obtained from the online database of the Statistics Division of the Food and Agriculture Organization of the United Nations (FAOSTAT). The target populations were 35 Asian countries that included Bangladesh, Brunei Darussalam, Cambodia, China, Democratic People's Republic of Korea, Fiji, India, Indonesia, Islamic Republic of Iran, Japan, Jordan, Kiribati, Kuwait, Kyrgyzstan, Lao People's Democratic Republic, Lebanon, Malaysia, Maldives, Mongolia, Myanmar, Nepal, Pakistan, Philippines, Republic of Korea, Samoa, Saudi Arabia, Solomon Islands, Sri Lanka, Syrian Arab Republic, Thailand, Timor-Leste, United Arab Emirates, Vanuatu, Viet Nam, and Yemen. The concentrations of spermine, spermidine, and putrescine in foods were obtained from published reports of concentrations measured in Japanese foods $[9,10]$. When these reports did not show the polyamine content of certain foods, we used additional data obtained from European studies [11,12] (Table 1). All the food items were categorized

Table 1. Polyamine contents in Asian foods (nmol/g or $\mathrm{nmol} / \mathrm{mL})^{\dagger}$

\begin{tabular}{|c|c|c|c|}
\hline Food items & Putrescine & Spermidine & Spermine \\
\hline \multicolumn{4}{|l|}{ Cereals } \\
\hline Barley & 17 & 16 & 20 \\
\hline Maize & 576 & 144 & 8 \\
\hline Millet & 19 & 63 & 48 \\
\hline Oats & 41 & 133 & 148 \\
\hline $\begin{array}{l}\text { Rice (milled } \\
\text { equivalent) }\end{array}$ & 8 & 7.5 & 1.5 \\
\hline Rye & 41 & 133 & 148 \\
\hline Sorghum & 14 & 12 & 0 \\
\hline Wheat & 19 & 29.5 & 0.5 \\
\hline Other cereals & 31.7 & 90 & 23.7 \\
\hline \multicolumn{4}{|l|}{ Vegetables } \\
\hline Cassava & 0 & 0 & 0 \\
\hline Cloves & 0 & 0 & 0 \\
\hline Onions & 29.5 & 86.5 & 4.5 \\
\hline Potatoes & 89 & 68 & 15.5 \\
\hline Pulses ${ }^{1}$ & 26 & 144 & 74 \\
\hline $\begin{array}{l}\text { Roots \& tuber } \\
\text { dry equiv }^{2}\end{array}$ & 118 & 109.3 & 19.8 \\
\hline $\begin{array}{l}\text { Sweet pota- } \\
\text { toes }\end{array}$ & 29 & 25.2 & 16.5 \\
\hline
\end{tabular}

\begin{tabular}{|c|c|c|c|}
\hline Tomatoes & 146.3 & 22.5 & 2.5 \\
\hline Vegetables $^{3}$ & 113.5 & 170.2 & 17.4 \\
\hline Yams & 73 & 89.5 & 2 \\
\hline Aquatic plants & 118 & 109.3 & 19.8 \\
\hline \multicolumn{4}{|l|}{ Fruits } \\
\hline Apples & 10 & 14 & 0.5 \\
\hline Bananas & 160 & 50 & 1.5 \\
\hline Grapefruit & 436 & 19.5 & 1.5 \\
\hline Grapes & 106 & 87 & 0 \\
\hline Lemons, limes & 390.5 & 19 & 4.5 \\
\hline $\begin{array}{l}\text { Oranges, } \\
\text { mandarins }\end{array}$ & 432 & 15.5 & 0 \\
\hline Pineapples & 46 & 30 & 0 \\
\hline Citrus, other ${ }^{4}$ & 460.2 & 26.5 & 0 \\
\hline Fruits, other ${ }^{5}$ & 74.5 & 55.4 & 4 \\
\hline \multicolumn{4}{|l|}{$\begin{array}{l}\text { Beans and } \\
\text { Nuts }\end{array}$} \\
\hline Beans $^{6}$ & 147 & 644.8 & 299.7 \\
\hline Groundnuts $^{7}$ & 18 & 110 & 88 \\
\hline Peas $^{8}$ & 367 & 341 & 32 \\
\hline Sesame seed & 29 & 126 & 22 \\
\hline Soybean & 297 & 909 & 235.5 \\
\hline $\begin{array}{c}\text { Sunflower } \\
\text { seed }\end{array}$ & 34 & 383 & 89 \\
\hline Tree nuts ${ }^{9}$ & 104.5 & 108.9 & 111.6 \\
\hline \multicolumn{4}{|l|}{ Seafoods } \\
\hline Cephalopods ${ }^{10}$ & 3.3 & 9.3 & 93.3 \\
\hline Crustaceans $^{11}$ & 26.5 & 0 & 0 \\
\hline Fish $^{12}$ & 27.2 & 37.1 & 53.1 \\
\hline Fish, oil & 0 & 0 & 0 \\
\hline Molluscs $^{13}$ & 19.7 & 143.5 & 383.5 \\
\hline $\begin{array}{l}\text { Aquatic ani- } \\
\text { mals and } \\
\text { others }{ }^{14}\end{array}$ & 26.3 & 55.1 & 87.2 \\
\hline \multicolumn{4}{|l|}{ Meat } \\
\hline Bovine meat & 18.5 & 17.5 & 149 \\
\hline $\begin{array}{c}\text { Mutton \& goat } \\
\text { meat }\end{array}$ & 8.2 & 39.7 & 131.3 \\
\hline Pig meat & 4.5 & 9.5 & 165 \\
\hline Poultry meat ${ }^{15}$ & 13.3 & 48.5 & 3.5 \\
\hline Meat, other & 11.5 & 26.7 & 194.2 \\
\hline Offal, edible ${ }^{16}$ & 63.8 & 188 & 825.8 \\
\hline \multicolumn{4}{|l|}{$\begin{array}{l}\text { Dairy prod- } \\
\text { ucts }\end{array}$} \\
\hline $\begin{array}{l}\text { Butter, ghee, } \\
\text { whey \& milk }\end{array}$ & 0 & 0 & 0 \\
\hline Cheese & 0 & 15 & 3.5 \\
\hline Cream & 0.3 & 0 & 0 \\
\hline
\end{tabular}




\begin{tabular}{cccc}
\hline Eggs & 6.5 & 2.5 & 2.5 \\
Vegetable oil and animal fat & & \\
Vegetable oil & 0 & 0 & 0 \\
Animal fat & 0 & 0 & 0 \\
$\quad$ Sugar \& & & & \\
Sweeteners & & & \\
$\quad$ Sugar \& & 3 & 0 & 0 \\
Sweeteners & & & \\
Beverages and & & 1 & 0 \\
stimulants & 153.3 & 1.5 & 0 \\
$\quad$ Beer & 49 & 96.3 & 72.8 \\
$\quad$ Wine & 49.5 & 0 & 0 \\
Tea leaf & 0 & 0 & 0 \\
Coffee & 0 & 80 & 45 \\
Other beve- & rages ${ }^{17}$ & 021 & 0 \\
Pepper & 0 & 0 \\
Pimento \& & Spices & & \\
\hline
\end{tabular}

$\dagger$ The average content of spermine, spermidine, and putrescine in each food item expressed as $\mathrm{nmol} / \mathrm{g}$ or $\mathrm{nmol} / \mathrm{mL}$ was calculated using data for foods available in Japan reported by K. Nishimura, et al., (Decrease in polyamines with aging and their ingestion from food and drink. J Biochem 2006; 139: 81-90) and N. Nishibori, et al., (Amounts of poly-amines in foods in Japan and intake by Japanese. Food Chem 2007; 100: 433-872). ${ }^{1}$ Field pies; ${ }^{2}$ Burdock root and lotus root; ${ }^{3}$ Asparagus, bean sprouts, beet, beetroot, broccoli, Brussel sprouts, butterbur, cabbage, carrot, cauliflower, celery, Chinese cabbage, green cabbage, red cabbage, chervil, chicory, cucumber, eggplant, escarole, green leek, leek, lettuce, mushrooms, parsley, pumpkin, spinach, radish, salsify, sorrel, watercress; ${ }^{4}$ Oranges, mandarins, and tangerines; ${ }^{5}$ Pear, strawberry, persimmon, fig, pomegranate, peach, blueberry, melon, watermelon, cherry, prune, durian, papaya, dragon fruit, kiwifruit, mango, and avocado; ${ }^{6}$ Adzuki bean, cow pea, and soybean; ${ }^{7}$ Peanut; ${ }^{8}$ Green peas; ${ }^{9}$ Almond, cashew, and pistachio nuts; ${ }^{10}$ Squid and octopus; ${ }^{11}$ Shrimp and crab; ${ }^{12}$ Horse mackerel, Japanese needlefish, mackerel, salmon, sardine, tuna, conger, angler, sweetfish, alfonsino, saury, shark, scabbard fish, yellowtail, swordfish, bonito, codfish, eel, and whitefish; ${ }^{13}$ Oyster, white scallop, coral scallop, and clam; ${ }^{14}$ Fish and shellfish; ${ }^{15}$ Chicken and duck; ${ }^{16}$ Beef liver, beef intestine, pork liver, chicken liver, chicken gizzard, and chicken heart; ${ }^{17}$ Soft drink and cocoa.

the following 12 groups for further analysies; including 1) Cereals, 2) Vegetables and starchy roots, 3) Fruits, 4) Beans, 5) Seafoods, 6) Meat, 7) Dairy products, 8) Eggs, 9) Vegetable oil and animal fat, 11) Sugar and sweeteners, and 12) Beverages and stimulants. As the data on food supply from the WHO does not necessarily indicate the absolute amount consumed by each nation, and in order to ascertain the features of dietary patterns, we used a relative measure of the amount of various foods, such as food consumption per energy quotient. GDP per capita in 2002 was obtained from the International Monetary Fund (IMF), and age-standardized mortality rates (per 100,000 population) due to cardiovascular diseases
(CVD) and cancer in 2002 and life expectancy at birth in 2006 were derived from the World Health Organization Statistical Information System (WHOSIS).

\subsection{Statistics}

The data were analyzed using the statistical package SPSS for Windows (SPSS Inc., Chicago, IL, USA). Pearson's correlation coefficients were calculated to examine the association between the relative amount of polyamine in foods, GDP per capita, and life expectancy. A $P$-value < 0.05 was considered statistically significant.

\section{RESULTS}

\subsection{Polyamine Contents in Asian Foods}

The average content of the three polyamines, putrescine, spermidine, and spermine in each food item is shown in Table 1. Polyamine content ranged widely among the foods, with several foods having increased polyamine concentrations. The highest putrescine levels were found in maize, citrus fruits, grapefruit, peas, soybeans, and other beans. Spermidine concentrations were high in soybeans, other beans, and vegetables, while spermine concentrations were high in edible offal, molluscs, meats, soybeans, and other beans. Generally, foods of plant origin tended to have higher contents of spermidine compared to spermine, whereas foods of animal origin had the opposite composition. The levels of all polyamines were very low or undetectable in vegetable oil, animal fat, sugar and sweeteners, eggs, and dairy products including butter, cream, whey, cow milk and infant milk formulas.

\subsection{Daily Amounts per capita and Amounts per $1000 \mathrm{kcal}$ of Polyamines}

Table 2 shows the daily amounts per capita and Table 3 shows the daily amounts per $1000 \mathrm{kcal}$ of the three polyamines in Asian countries. The average estimated daily intake of putrescine, spermidine, spermine, and total polyamines in Asian countries were $106 \mu \mathrm{mol}, 91 \mu \mathrm{mol}$, $38 \mu \mathrm{mol}$ and $235 \mu \mathrm{mol}$, respectively. Putrescine, spermidine, and spermine accounted for $44 \%, 39 \%$, and $17 \%$ of total polyamine intake, respectively. The amounts of putrescine, spermidine, spermine, and the sum of the three polyamines per $1000 \mathrm{kcal}$ energy were $39,34,14$, and $87 \mu \mathrm{mol} /$ day.

\subsection{Sources of Polyamines}

The proportions of the three polyamines provided by each food group are shown in Figure 1. Overall, vegetables provided the largest amount of putrescine and sper- 
Table 2. The daily amounts of polyamines in each food group.

\begin{tabular}{|c|c|c|c|c|}
\hline $\mathrm{c}$ & Amount & Putrescine & Spermidine & Spermine \\
\hline & (g/day) & ( $\mu \mathrm{mol} /$ day $)$ & ( $\mu \mathrm{mol} / \mathrm{day})$ & ( $\mu \mathrm{mol} /$ day) \\
\hline Cereals & $417.4 \pm 101.2$ & $26.04 \pm 35.19$ & $12.28 \pm 8.63$ & $0.92 \pm 1.17$ \\
\hline Vegetables and roots & $497.6 \pm 290.0$ & $48.40 \pm 30.81$ & $59.70 \pm 35.20$ & $8.68 \pm 4.90$ \\
\hline Fruits & $172.0 \pm 116.3$ & $23.85 \pm 19.19$ & $6.72 \pm 5.06$ & $0.32 \pm 0.25$ \\
\hline Beans & $28.6 \pm 30.9$ & $2.24 \pm 2.87$ & $6.03 \pm 9.24$ & $2.33 \pm 3.14$ \\
\hline Seafoods & $75.4 \pm 97.4$ & $1.86 \pm 2.60$ & $2.80 \pm 3.65$ & $4.64 \pm 5.80$ \\
\hline Meat & $89.7 \pm 67.5$ & $1.30 \pm 1.09$ & $3.64 \pm 3.34$ & $21.34 \pm 16.73$ \\
\hline Dairy products & $138.8 \pm 136.5$ & 0 & $0.04 \pm 0.09$ & $0.01 \pm 0.02$ \\
\hline Eggs & $14.2 \pm 13.8$ & $0.09 \pm 0.09$ & $0.04 \pm 0.03$ & $0.01 \pm 0.01$ \\
\hline Vegetable oil & $21.7 \pm 14.3$ & 0 & 0 & 0 \\
\hline Animal fat & $5.1 \pm 6.5$ & 0 & 0 & 0 \\
\hline Sugar and sweeteners & $63.2 \pm 36.1$ & $0.19 \pm 0.11$ & 0 & 0 \\
\hline Beverages and stimulants & $34.6 \pm 42.1$ & $1.87 \pm 2.84$ & $0.11 \pm 0.17$ & $0.04 \pm 0.01$ \\
\hline Total & $1558.2 \pm 480.9$ & $105.85 \pm 52.48$ & $91.36 \pm 41.61$ & $38.29 \pm 19.61$ \\
\hline
\end{tabular}

Per-capita daily availability of amount of food and the amount of putrescine, spermidine, and spermine from each food group are expressed as the mean \pm standard deviation (SD). Values $<0.001$ are expressed as 0 .

Table 3. The daily amounts per $1000 \mathrm{kcal}$ of polyamines in each food group.

\begin{tabular}{ccccc}
\hline Food groups & Amount & Putrescine & Spermidine & Spermine \\
\hline & $(\mathrm{g} / 1000 \mathrm{kcal})$ & $(\mu \mathrm{mol} / 1000 \mathrm{kcal})$ & $(\mu \mathrm{mol} / 1000 \mathrm{kcal})$ & $(\mu \mathrm{mol} / 1000 \mathrm{kcal})$ \\
Cereals & $158.7 \pm 41.4$ & $9.99 \pm 13.26$ & $4.64 \pm 3.25$ & $0.35 \pm 0.42$ \\
Vegetables and roots & $183.3 \pm 104.3$ & $17.68 \pm 10.49$ & $21.89 \pm 12.01$ & $3.22 \pm 1.82$ \\
Fruits & $62.7 \pm 38.2$ & $8.59 \pm 6.24$ & $2.46 \pm 1.73$ & $0.12 \pm 0.09$ \\
Beans & $10.2 \pm 10.4$ & $0.84 \pm 1.17$ & $2.32 \pm 3.93$ & $0.89 \pm 1.35$ \\
Seafoods & $28.2 \pm 36.8$ & $0.70 \pm 0.98$ & $1.04 \pm 1.37$ & $1.72 \pm 2.14$ \\
Meat & $32.7 \pm 24.9$ & $0.47 \pm 0.42$ & $1.32 \pm 1.26$ & $7.74 \pm 6.07$ \\
Dairy products & $50.4 \pm 47.7$ & $0.0 \pm 0.0$ & $0.01 \pm 0.03$ & $0.003 \pm 0.007$ \\
Eggs & $5.1 \pm 4.8$ & $0.03 \pm 0.03$ & $0.01 \pm 0.01$ & $0.003 \pm 0.002$ \\
Vegetable oil & $7.9 \pm 4.7$ & 0 & 0 & 0 \\
Animal fat & $1.8 \pm 2.3$ & 0 & 0 & 0 \\
Sugar and sweeteners & $23.2 \pm 12.5$ & $0.07 \pm 0.04$ & 0 & 0 \\
Beverages and stimulants & $12.6 \pm 14.6$ & $0.69 \pm 1.01$ & $0.04 \pm 0.06$ & $0.01 \pm 0.03$ \\
Total & $576.8 \pm 128.7$ & $39.07 \pm 17.98$ & $33.74 \pm 14.35$ & $14.05 \pm 6.60$ \\
\hline Percal
\end{tabular}

Per-capita availability of the amount of food and the amount of putrescine, spermidine, and spermine per person are listed by food category. The daily amounts per $1000 \mathrm{kcal}$ are expressed as the mean $\pm \mathrm{SD}$. Values $<0.001$ are expressed as 0

A

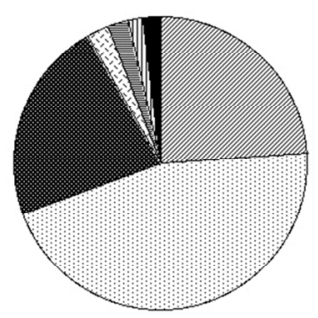

B

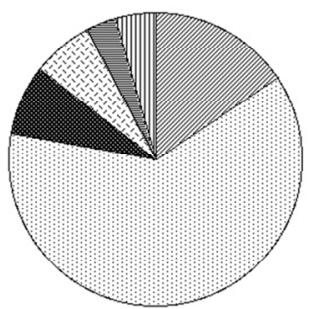

C

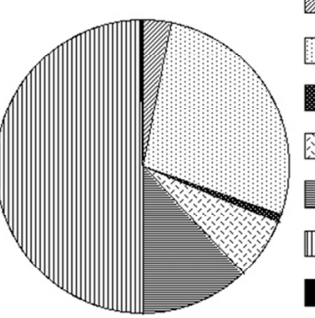

Cereals

Vegetables and roots

Fruits

Beans

Fish, shellfish and seafoods

而 Meat

Others

Figure 1. The contribution of each food group to the amount of putrescine (A), spermidine (B) and spermine (C). 
midine, and also provided the second largest amount of spermine $(45.5 \%$ of putrescine, $62.2 \%$ of spermidine, and $27.2 \%$ of spermine). Other important sources of putrescine were cereals and fruits, which provided $24.0 \%$ and $22.3 \%$ of total putrescine, respectively. Cereals, fruits, and beans supplied $15.5 \%, 7.7 \%$, and $6.6 \%$ of total spermidine, respectively. Animal meats were the biggest source of spermine, and provided $50 \%$ of total spermine.

\subsection{Associations between the Amounts of Putrescine, Spermidine, and Spermine per Total Energy and GDP per capita}

The GDPs of the Democratic People's Republic of Korea and Timor-Leste could not be obtained. These two countries were therefore excluded from the analyses which subsequently included 33 countries. The GDP data were transformed to natural logarithms to approximate a normal distribution. Pearson's correlation coefficients were calculated to investigate the relationship between polyamine amount per food energy (1000 kcal) and GDP. As shown in Table 4, GDP per capita correlated positively with all three polyamines, with different levels of correlation being observed. Although the correlation coefficients between GDP and spermidine and putresine per energy quotient were $<0.4$ with $p$ values $<0.05$, spermine per energy quotient showed a strong positive correlation with GDP.

\subsection{Correlation among the Amount of Polyamine, GDP, and Health Status}

GDP was associated positively with life expectancy $(\mathrm{r}=$ $0.890, p<0.001$ ) and negatively with mortality due to cardiovascular diseases $(\mathrm{r}=-0.640, p<0.001)$. Life expectancy was associated negatively with CVD mortality $(r=-0.674, p<0.001)$. Although no significance associations were found, the correlation coefficients between CVD mortality and spermine/energy, spermidine/ energy, putrescine/energy, spermine plus spermidine/ energy, and total amount of all three polyamines/energy all had negative values $(\mathrm{r}=-0.276,-0.057,-0.035$, -0.154 , and -0.103 , respectively). No significant association was found between life expectancy and cancer mortality. As shown in Table 4, GDP and life expectancy were associated positively with the total amount of food polyamine per energy, with various levels of correlation being observed.

\section{DISCUSSION}

Reference to our previous report on European foods [19] showed that although there were many similarities in the
Table 4. Correlation between polyamine/energy and GDP and life expectancy.

\begin{tabular}{lcccc}
\hline & \multicolumn{2}{c}{ GDP } & \multicolumn{2}{c}{ Life expectancies } \\
\hline & $\mathrm{r}$ & $P$ & $\mathrm{r}$ & $P$ \\
Putrescine / energy & 0.366 & 0.036 & 0.232 & 0.181 \\
Spermidine / energy & 0.386 & 0.026 & 0.308 & 0.072 \\
Sermine / energy & 0.607 & $<0.001$ & 0.585 & $<0.001$ \\
Spermine plus & 0.532 & 0.001 & 0.453 & 0.006 \\
spermidine / energy & & & & \\
Polyamine / energy & 0.480 & 0.004 & 0.367 & 0.030 \\
\hline
\end{tabular}

The correlation between each polyamine / energy and GDP (natural logarithm) was examined in 33 countries, as the GDP of the Democratic People's Republic of Korea and Timor-Leste could not be obtained. $r$ indicates the correlation coefficient of the linear regression between polyamine/energy and GDP or life expectancy.

proportions of supplied foods, there were striking differences in the higher amounts of dairy products and animal-derived products consumed in European countries, whereas consumption of cereals was higher in Asian countries. Similarly, polyamine concentrations in Japanese foods $[9,10]$ were similar to those in European foods [11,12], whereas in some foods, especially cheese, the concentrations were markedly different. These varia-tions in polyamine content could be explained by the effects of food processing and storage changes, and one of the weaknesses of the present study was the inability to comprehend these changes. However, the estimated daily amount of food polyamines in Asian countries was similar to those contained in a previous report on Japanese foods [9] in which the daily amount of supplied putrescine, spermidine, and spermine per person were 113,82 , and $39 \mu \mathrm{mol}$, respectively. In that study, putrescine, spermidine, and spermine accounted for $45 \%, 37 \%$ and $18 \%$ of total daily polyamine supply in Japanese diets, respectively. The daily amount of polyamine availability from foods in Asian countries was considerably lower than that reported in European countries, especially countries with a higher GDP (350-500 $\mu \mathrm{mol} /$ day/person) [20,21]. However, the proportions of each of the three polyamines relative to total polyamines were similar to those in European countries [20,21]. The lower amount of total polyamine availability appeared to be due to the lower amount of total food supply in Asian countries, as the amounts of spermine and spermidine per food energy in Asian countries were higher than those in European countries, while the sum of the total amount of the three polyamines per energy was similar to European and Western countries with a lower GDP [19].

The results of the present study using databases for Asian countries were relatively similar to those reported in earlier studies in European and Western countries in which socio-economic status showed a close positive association with longevity and a close negative associa- 
tion with CVD mortality [13-18]. The results of the present study also indicated that reducing the incidence of CVD is very important for improving health status and prolonging lifespan, even in Asian countries. Studies using personal databases have shown decreases in CVD incidence and increases in life span are often associated with socioeconomic status [13-18]. Although the factors affecting health condition according to socioeconomic status are not fully understood, the present study showed that the amount of polyamine in foods was associated closely with GDP per capita. A very interesting finding in our study was that the amount of food polyamine per energy quotient was associated not only positively with GDP but also negatively with CVD incidence. As the current study was an ecological investigation, it would therefore be expected there were potential confounding factors in these associations. However, recent basic research studies have shown that increased polyamine intake prolongs the longevity of some small organisms and rodents $[1,2]$, and therefore increased polyamine intake may theoretically help maintain vascular health by increasing the amount of arginine available for nitric oxide (NO) synthesis [22-25]. These findings and those of the present study suggest a possible role of food polyamines on human health.

\section{REFERENCES}

[1] Eisenberg, T., Knauer, H., Schauer, A., Buttner, S., Ruckenstuhl, C., Carmona-Gutierrez, D., Ring, J., Schroeder, S., Magnes, C., Antonacci, L., Fussi, H., Deszcz, L., Hartl, R., Schraml, E., Criollo, A., Megalou, E., Weiskopf, D., Laun, P., Heeren, G., Breitenbach, M., Grubeck-Loebenstein, B., Herker, E., Fahrenkrog, B., Frohlich, K.U., Sinner, F., Tavernarakis, N., Minois, N., Kroemer, G. and Madeo, F. (2009) Induction of autophagy by spermidine promotes longevity. Nature Cell Biology, 11, 1305-1314.

[2] Soda, K., Dobashi, Y., Kano, Y., Tsujinaka, S. and Konishi, F. (2009) Polyamine-rich food decreases age-associated pathology and mortality in aged mice. Experimental Gerontology, 44, 727-732.

[3] Quemener, V., Chamaillard, L., Brachet, P., Havouis, R. and Moulinoux, J.P. (1994) Involvement of polyamines in malignant proliferative processes: Antineoplastic effects of a polyamine deficiency. Bulletin de l'Academie Nationale de Medecine, 178, 1591-1605.

[4] Quemener, V., Blanchard, Y., Chamaillard, L., Havouis, R., Cipolla, B. and Moulinoux, J.P. (1994) Polyamine deprivation: A new tool in cancer treatment. Anticancer Research, 14, 443-448.

[5] Pegg, A.E. (1988) Polyamine metabolism and its importance in neoplastic growth and a target for chemotherapy. Cancer Research, 48, 759-774.

[6] Marton, L.J. and Pegg, A.E. (1995) Polyamines as targets for therapeutic intervention. Annual Review of Pharmacology and Toxicology, 35, 55-91.
[7] Bardocz, S., White, A., Grant, G., Brown, D.S., Duguid, T.G. and Pusztai, A. (1996) Uptake and bioavailability of dietary polyamines. Biochemical Society Transactions, 24, 226S.

[8] Soda, K., Kano, Y., Sakuragi, M., Takao, K., Lefor, A. and Konishi, F. (2009) Long-term oral polyamine intake increases blood polyamine concentrations. Journal $\mathrm{Nu}$ trition Science and Vitaminology (Tokyo), 55, 361-366.

[9] Nishibori, N., Fujihara, S. and Akatuki, T. (2007) Amounts of polyamines in foods in Japan and intake by Japanese. Food Chemistry, 100, 491-497.

[10] Nishimura, K., Shiina, R., Kashiwagi, K. and Igarashi, K. (2006) Decrease in polyamines with aging and their ingestion from food and drink. Journal of Biochemistry, 139, 81-90.

[11] Cipolla, B.G., Havouis, R. and Moulinoux, J.P. (2007) Polyamine contents in current foods: A basis for polyamine reduced diet and a study of its long term observance and tolerance in prostate carcinoma patients. Amino Acids, 33, 203-212.

[12] Bardócz, S., Grant, G., Brown, D.S., Ralph, A. and Pusztai, A. (1993) Polyamines in food-implications for growth and health. Journal of Nutrition Biochemistry, 4, 66-71.

[13] Cooper, R., Cutler, J., Desvigne-Nickens, P., Fortmann, S. P., Friedman, L., Havlik, R., Hogelin, G., Marler, J., McGovern, P., Morosco, G., Mosca, L., Pearson, T., Stamler, J., Stryer, D. and Thom, T. (2000) Trends and disparities in coronary heart disease, stroke, and other cardiovascular diseases in the United States: Findings of the national conference on cardiovascular disease prevention. Circulation, 102, 3137-3147.

[14] Kaplan, G.A. and Keil, J.E. (1993) Socioeconomic factors and cardiovascular disease: a review of the literature. Circulation, 88, 1973-1998.

[15] Rooks, R.N., Simonsick, E.M., Miles, T., Newman, A., Kritchevsky, S.B., Schulz, R. and Harris, T. (2002) The association of race and socioeconomic status with cardiovascular disease indicators among older adults in the health, aging, and body composition study. Journals of Gerontology, 57, S247-256.

[16] Janssen, F., Kunst, A.E. and Mackenbach, J.P. (2006) Association between gross domestic product throughout the life course and old-age mortality across birth cohorts: parallel analyses of seven European countries, 1950-1999. Social Science \& Medicine, 63, 239-254.

[17] Tresserras, R., Canela, J., Alvarez, J., Sentis, J. and Salleras, L. (1992) Infant mortality, per capita income, and adult illiteracy: an ecological approach. American Journal of Public Health, 82, 435-438.

[18] Beckfield, J. (2004) Does income inequality harm health? New cross-national evidence. Journal of Health \& Social Behavior, 45, 231-248.

[19] Binh, P.N.T., Soda, K. and Kawakami, M. (2010) Gross domestic product and dietary pattern among 49 Western countries with a focus on polyamine intake. Health, 2 , in press.

[20] Bardocz, S., Duguid, T.J., Brown, D.S., Grant, G., Pusztai, A., White, A. and Ralph, A. (1995) The importance of dietary polyamines in cell regeneration and growth. British Journal of Nutrition, 73, 819-828.

[21] Zoumas-Morse, C., Rock, C.L., Quintana, E.L., Neuh- 
ouser, M.L., Gerner, E. W. and Meyskens, F.L. (2007) Development of a polyamine database for assessing dietary intake. Journal of the American Dietetic Association, 107, 1024-1027.

[22] Soda, K. (2010) Polyamine intake, dietary pattern, and cardiovascular disease. Medical Hypotheses, 75, 299-301.

[23] Lefer, A.M. and Lefer, D.J. (1996) The role of nitric oxide and cell adhesion molecules on the microcirculation in ischaemia-reperfusion. Cardiovasc Research, 32,
743- 751.

[24] Drexler, H., Zeiher, A.M., Meinzer, K. and Just, H. (1991) Correction of endothelial dysfunction in coronary microcirculation of hypercholesterolaemic patients by L-arginine. Lancet, 338, 1546-1550.

[25] Cooke, J.P., Singer, A.H., Tsao, P., Zera, P., Rowan, R.A., and Billingham, M.E. (1992) Antiatherogenic effects of L-arginine in the hypercholesterolemic rabbit. Journal of Clinical Investigation, 90, 1168-1172. 